\title{
FREQUENCY OF FLU-LIKE SYMPTOMS DURING THE PANDEMIC IN RHEUMATIC PATIENTS WITH ASSOCIATED COMORBIDITIES: AN ANALYSIS OF THE PINOTTI II PROJECT
}

João Pedro de Oliveira Aucélio1,^, Gustavo Araújo do Nascimento Santos ${ }^{1}$, Bruna de Paula Gonçalves Sousa Lyra ${ }^{1}$, Paulo Ricardo Guimarães Rocha Storni², Gabriela Brill Ney ${ }^{3}$, Maria Teresa Aires Cabral Dias ${ }^{4}$, Beatriz Toledo Mendes ${ }^{1}$, Kevin Haley Barbosa ${ }^{1}$, Ana Beatriz Caetano Vieira ${ }^{4}$, Tamires Martinelli de Oliveira Ferraz ${ }^{1}$, Beatriz Pires Paes ${ }^{1}$, Maurício Silva de Jesus ${ }^{1}$, Maria Luiza Pimentel de Oliveira ${ }^{1}$, Nicole de Almeida Castro Kammoun ${ }^{1}$, Viviane Cristina Uliana Peterle ${ }^{1}$, Ana Paula Gomides ${ }^{1}$

1.Centro Universitário de Brasília, Brasília (DF), Brazil; 2.Centro Universitário Euro-Americano, Brasília (DF), Brazil; 3.Centro Universitário do Planalto Central Apparecido dos Santos, Brasília (DF), Brazil; 4.Universidade Católica de Brasília, Brasília (DF), Brazil.

*Corresponding author: jp.aucelio@gmail.com

\section{BACKGROUND}

COVID-19 is a highly contagious disease, which caused a pandemic with several consequences. The infection with the new coronavirus is capable of developing a wide range of flu-like clinical conditions and to affect different organs. Based on this, we sought to evaluate if the presence of comorbidities in the clinical condition of an individual supports the increased number of symptoms in flu-like syndromes during the COVID-19 pandemic in rheumatologic patients.

\section{METHODS}

This study was based on the analysis of descriptive statistical data from the Pinotti II Project, which involved regular monitoring, every 14 days, via phone calls, for a prospective analysis of rheumatologic patients living in the Federal District. Therefore, the RedCap digital platform was used to store the data collected in the five interviews carried out from April to June 2020. In each interview, questionnaires were used covering sociodemographic and health data of each individual, including questions about associated comorbidities and flu symptoms during the COVID-19 pandemic.

\section{RESULTS}

The frequency of comorbid symptoms in rheumatologic patients was evaluated. To achieve this, a total of 362 patients with rheumatologic diseases were included, of which 22 (6.07\%) had heart disease, 22 (6.07\%) had diabetes mellitus, 80 (22\%) had systemic arterial hypertension, 32 (8.83\%) had kidney disease and 26 (7.18\%) had pulmonary disease. In the comparative analysis, based on Table 1, the maximum frequency of 1.33 symptom in rheumatologic patients with heart disease when compared to the maximum frequency of 1 symptom in rheumatologic patients without heart disease is an aspect that stands out. Furthermore, it was possible to evidence that comorbidities do not affect flu-like clinical conditions on average, once the frequency of symptoms is lower when associated diseases are present. The kidney disease is the only exception, since when associated with rheumatologic disease increases the frequency of flu-like symptoms on average.

Table 1. Summary measures of the frequency of symptoms by comorbidities.

\begin{tabular}{|c|c|c|c|c|c|c|c|c|}
\hline Comorbidities & Average & Standard Deviation & Minimum & Maximum & 1st quartile & Median & 3rd quartile & $\mathrm{N}$ \\
\hline \multicolumn{9}{|c|}{ Heart disease } \\
\hline no & 0.17 & 0.29 & 0.00 & 1.00 & 0.00 & 0.00 & 0.25 & 340 \\
\hline yes & 0.15 & 0.31 & 0.00 & 1.33 & 0.00 & 0.00 & 0.23 & 22 \\
\hline \multicolumn{9}{|c|}{ Diabetes } \\
\hline no & 0.17 & 0.29 & 0.00 & 1.33 & 0.00 & 0.00 & 0.25 & 340 \\
\hline yes & 0.12 & 0.26 & 0.00 & 0.80 & 0.00 & 0.00 & 0.08 & 22 \\
\hline \multicolumn{9}{|c|}{ Systemic arterial hypertension } \\
\hline no & 0.18 & 0.30 & 0.00 & 1.33 & 0.00 & 0.00 & 0.25 & 282 \\
\hline yes & 0.13 & 0.24 & 0.00 & 1.00 & 0.00 & 0.00 & 0.20 & 80 \\
\hline \multicolumn{9}{|c|}{ Kidney disease } \\
\hline no & 0.17 & 0.29 & 0.00 & 1.33 & 0.00 & 0.00 & 0.25 & 330 \\
\hline yes & 0.20 & 0.24 & 0.00 & 0.80 & 0.00 & 0.00 & 0.40 & 32 \\
\hline \multicolumn{9}{|c|}{ Pulmonary disease } \\
\hline no & 0.18 & 0.29 & 0.00 & 1.33 & 0.00 & 0.00 & 0.25 & 336 \\
\hline yes & 0.12 & 0.18 & 0.00 & 0.67 & 0.00 & 0.00 & 0.20 & 26 \\
\hline
\end{tabular}

\section{CONCLUSION}

The presence of comorbidities in rheumatologic patients did not significantly increase the frequency of flu-like symptoms.

\section{KEYWORDS}

Pinotti Il project, Flu-like symptoms, Comorbidities, Rheumatic patients. 